\title{
MEMAJUKAN UKM CONFETTI DENGAN MEMANFAATKAN TEKNOLOGI DIGITAL
}

\author{
Ardijan Handijono, Rudy Irawan Gunarto, Eka Kusuma Dewi, \\ Samsul Marpitasa, Yunita Kwartarani \\ dosen00853@unpam.ac.id, dosen02327@unpam.ac.id,dosen00955@unpam.ac.id, \\ dosen01718@unpam.ac.id, dosen01979@unpam.ac.id \\ Akuntansi S1, Ekonomi, Universitas Pamulang \\ Korespondensi Ardijan Handijono, email: dosen00853@unpam.ac.id
}

\begin{abstract}
Abstrak
Mitra PKM kami adalah perusahaan keluarga yang bergerak di bidang pembuatan seprei berbahan kaos, memiliki merk dagang "confetti" di Depok. Masalah yang mereka hadapi antara lain masih terbatasnya keahlian mereka dalam memanfaatkan teknologi untuk pemasaran, Job description karyawan yang masih tumpang tindih, serta manajemen keuangan yang hanya menggunakan pembukuan sederhana. Metode pendekatan yang digunakan dalam kegiatan PKM adalah brainstorming untuk membuka mindset tentang pentingnya manajemen usaha lebih professional, mengajarkan teknologi yang menunjang pemasaran, dan pembuatan laporan keuangan.yang benar. Solusi yang ditawarkan antara lain dengan mengusulkan penggunaan teknologi kekinian, menyusun struktur organisasi dengan penjelasan tugas masing-masing peran serta mengajarkan cara penyusunan laporan keuangan yang benar.
\end{abstract}

Kata Kunci: Manajemen Keuangan, Digital Marketing, SAAS.

\section{Abstract}

Our PKM partners are a family company engaged in the manufacture of T-shirt sheets, which have the trademark "confetti" in Depok area. The problems they face include their limited expertise in utilizing technology for marketing, overlapping employee job descriptions, and financial management which only uses simple bookkeeping.The approach method used in PKM activities is brainstorming to open a mindset about the importance of more professional business management, teaching technology that supports marketing, and making correct financial reports. The solutions offered include proposing the use of current technology, compiling an organizational structure with job description of each role and teaching how to prepare proper financial reports.

Keywords: Financial management Digital Marketing, SAAS. 


\section{PENDAHULUAN}

Usaha Kecil dan Menengah (UKM) memegang peranan penting dalam perekonomian di Indonesia. Kemenkop UKM melansir sebanyak 3,79 juta usaha mikro, kecil, dan menengah (UMKM) sudah memanfaatkan platform online dalam memasarkan produknya. (Maradina, Shanti, Nadi, Kusumawardhany, \& Damayanti, 2019). Hal ini sejalan dengan hasil observasi kami, bahwa UMKM semakin tumbuh dan berkembang. Hal ini ditandai dengan semakin meningkatnya pendapatan daerah. (Kristiyanti, 2012) Namun maraknya UKM ini tidak dibarengi dengan kompetensi yang cukup para pelaku UKM untuk dapat mengelola bisnisnya secara efektif dan efisien, sehingga beberapa UKM akhirnya kalah bersaing dan tutup. Kami tim dosen program studi Akuntansi telah melakukan Penelitian dan Pengabdian Kepada masyarakat tentang Usaha Kecil dan Menengah pada Usaha pembuatan Sprei Kaos Confetti yang berada di Jalan Radar AURI, Depok. Usaha pembuatan sprei "Confetti" sudah berdiri sejak November 2015, saat ini jumlah karyawan tetap ada 11 orang dan 2 orang karyawan kontrak. UKM ini mampu memberdayakan masyarakat sekitar dalam meningkatkan ekonomi keluarga. Usaha ini didirikan oleh Sufia
Bintari dan Erlin Reni. Pada akhirnya usaha sprei ini semakin maju dan berkembang. Potensi dan sumber daya alam yang ada di sekitar sangat membantu berkembangnya usaha sprei ini. Pemilihan bahan kaos sebagai bahan dasar sprei menjadi pertimbangan pemilik untuk bersaing dengan sprei yang berbahan dasar katun. Tim kami bermaksud membantu UKM sprei Confetti untuk meberikan penyuluhan agar UKM ini semakin maju dan berkembang.

Universitas Pamulang (UNPAM) merupakan kampus yang berdiri di bawah naungan Yayasan Sasmita Jaya yang beralamat di Jl. Surya Kencana No.1 pamulang dengan mengemban visi "Bermutu dalam pengembangan pendidikan, penelitian, dan pengabdian terjangkau seluruh lapisan masyarakat berlandaskan ridha Tuhan yang maha Esa". UNPAM membuka diri untuk melakukan berbagai kerjasama dengan berbagai pihak dalam rangka pengembangan ilmu, institusi, teknologi dan seni dalam rangka pelaksanaan Tri Dharma Perguruan Tinggi yakni Pendidikan, Penelitian dan Pengabdian. UNPAM sudah mempunyai jaringan dengan berbagai lembaga lain yakni pemerintah pusat, pemerintah propinsi, pemerintah kabupaten, dunia usaha, swasta, maupun, dengan, masyarakat. 


\section{METODE}

Tempat dilaksanakkannya PKM adalah pada Kantor/Workshop Usaha pembuatan Sprei Kaos Confetti yang berada di Jalan Radar AURI, Depok, dilaksanaan pada tanggal 12-17 Nopember 2019.

Untuk dapat memberikan solusi dari beberapa masalah yang dihadapi oleh UKM Confetti kami mengajukan beberapa pendekatan yakni dengan mengadakan kegiatan-kegiatan sebagai berikut:

i. Melakukan pengamatan dan wawancara ke beberapa pegawai di tempat Workshop.

ii. Presentasi mengenai pengertian Akuntasi dan Penggunaannya dalam mengelola Keuangan Perusahaan. (Edmonds, Tsay, \& Olds, 2011)

iii. Presentasi mengenai Digital Marketing untuk meningkatkan penjualan. (Kingsnorth, 2019)

iv. Diskusi mengenai cara meningkatkan rating portal perusahaan pada mesin pencari di dunia maya.

v. Diskusi mengenai cara mengurus badan hukum perusahaan dan Perpajakan.

vi. Tanya jawab.

vii. Melakukan pemantauan dan pembinaan
Pendekatan ini telah disetujui dan sudah dijalankan dengan mitra diharapkan dapat mencapai tujuan utama yang sudah dipaparkan

\section{HASIL DAN PEMBAHASAN}

Solusi yang kami tawarkan atau kami usulkan dapat dikelompokkan dalam 3 aspek yaitu People, Process, dan Technology sebagai berikut :

\section{People}

Hal pertama yang perlu ditingkatkan adalah kualitas sumber daya manusianya. Sumber daya manusia adalah usaha manusia untuk meningkatkan guna suatu barang serta mengkordinasikan dan mengelola faktor produksi dalam menghasilkan barang dan jasa. Ketika sumber daya manusia yang dimiliki oleh UKM tersebut dinilai cakap maka hal selanjutnya yang perlu diperhatikan ialah :

a. Intensifikasi - merupakan upaya untuk meningkatkan hasil produksi dengan cara memperbaiki metode kerja dan meningkatkan produktivitas faktor produksi.

b. Ekstensifikasi - sebagai cara untuk meningkatkan kualitas dan kuantitas produksi. Dengan kata lain adalah upaya untuk meningkatkan hasil produksi 
dengan cara menambah faktor-faktor produksi.

\section{Process}

Proses yang paling berpengaruh pada seluruh organisasi adalah proses yang terjadi pada manajemen, perihal manajemen oleh pengusaha kecil umumnya kurang diperhatikan karena semua hal dikerjakan sendiri mulai dari manajemen pemasaran, manajemen produksi, manajemen SDM sampai manajemen keuangan. Untuk bisa berkembang pelaku usaha kecil harus mulai bisa mendelegasikan sebagian aspek manajemen usahanya ke pihak lain sehingga mereka bisa fokus memikirkan ke arah pengembangan usaha. Solusi yang kami tawarkan kepada mitra adalah memberikan pelatihan manajemen bisnis meliputi perencanaan sampai pengendalian baik dalam aspek produksi maupun manajemen.

a. Tertib Administrasi - akan bermanfaat bagi pelaku UKM yang pengembangan usahanya sehingga di awal usaha akan lebih tertib administrasinya. Sehingga semua transaksi bisnis dapat dicatat untuk di-review. Kondisi yang biasa terjadi umumnya antara kepentingan bisnis dan rumah tangga tercampur, sehingga di sinilah diperlukan peran manajemen.

b. Kreatif - Pengembangan kreativitas diperlukan, karena biasanya saat bisnis itu berdiri akan ada bisnis sejenis di lokasi yang berdekatan. Saat itulah perlu ada pengembangan kreativitas sebagai pembeda dari yang lain.

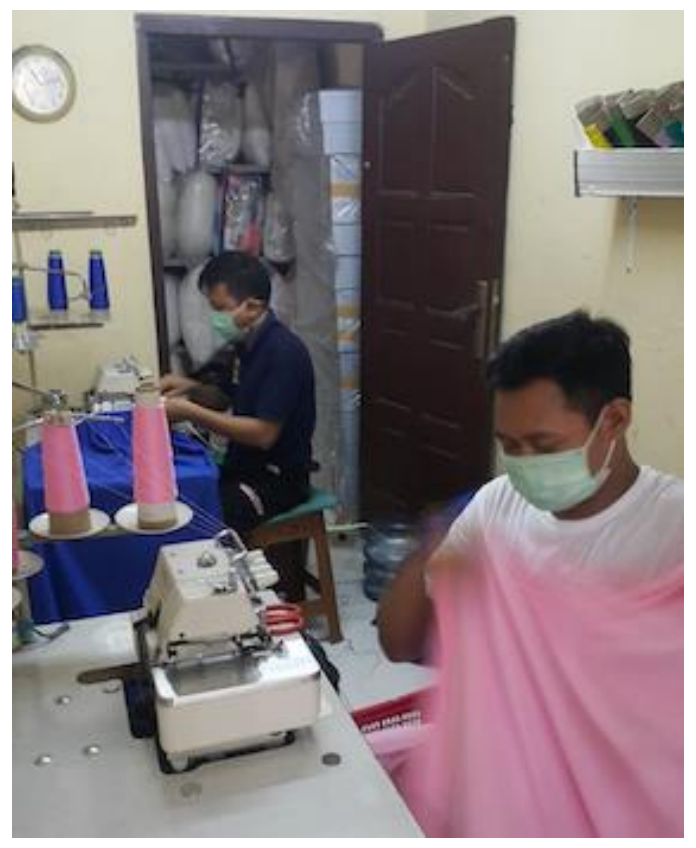

Gambar - 1

Karyawan Confetti sedang bekerja

c. Fokus - Pengembangan usaha yang dilakukan disesuaikan dengan usaha yang sudah ada, sehingga meskipun ada usaha lain yang bagus perkembangannya tetap harus disesuaikan dengan kondisi usaha. Adapun unsur-unsur fokus pada pemasaran ada tiga orientasi yaitu :

\section{- Berorientasi pada Konsumen}

Bila UKM benar- benar ingin memperhatikan konsumen, pelaku UKM harus: 
i. Menentukan Kebutuhan pokok (basic need) dari pembeli yang akan dilayani dan dipenuhi.

ii. Menentukan kelompok pembeli yang akan dijadikan sasaran penjualan bahkan kebutuhan tertentu dari kelompok pembeli tersebut.

iii. Menentukan produk dan program pemasarannya untuk memenhi kebutuhan yang berbeda-beda di pasarkan dengan program pemasaran yang berlainan.

iv. Mengadakan penelitian kepada konsumen untuk mengukur, menilai dan menafsirkan kualitas produk yang dipasarkan.

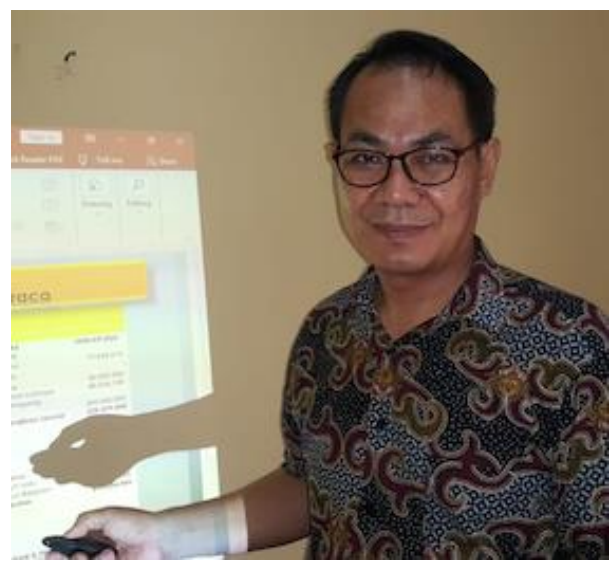

Gambar - 2

Presentasi mengenai

Dasar-Dasar Akuntasi

- Penyusunan kegiatan pemasaran secara integral
Pengintegrasian kegiatan pemasaran berarti bahwa setiap orang dan setiap bagian dalam perusahaan turut berkecimpung dalam usaha yang terkoordinir untuk memberikan kepuasan konsumen sehingga tujuan perusahaan dapat direalisir. Selain itu juga terdapat penyesuaian dan koordinasi antara produk harga saluran distribusi dan promosi untuk menciptakan hubungan pertukaran kuat dengan konsumen artinya harga jual harus sesuai dengan kualitas produk. Promosi harus disesuaikan dengan saluran distribusi harga dan kualitas produk dan sebagainya.

\section{- Mengutamakan Kepuasan}

\section{Konsumen}

Faktor yang akan menentukan apakah UKM dalam jangka panjang mendapatkan laba adalah banyak sedikitnya kepuasan konsumen yang dapat dipenuhi. Ini tidaklah berarti bahwa UKM harus mendapatkan laba dengan cara memberikan kepuasan kepada konsumen.

\section{Technology.}

Mengikuti Perkembangan Teknologi dalam Bisnis dapat membantu UKM untuk mengembangkan bisnis baik dalam hal administrasi, transaksi, 
keuangan, komunikasi, promosi dan penjualan. Berikut beberapa teknologi yang dapat diterapkan untuk memajukan UKM Confetti:

a. Menggunakan berbagai media sosial seperti Facebook, Twiter, Instagram, dsb. untuk memperkenalkan produkproduknya, Memaksimalkan manfaat internet untuk mempopulerkan kelebihan produk - produknya dibandingkan pesaing, mengelola web site perusahaan agar selalu up to date. (Evans, 2010)

b. Untuk menaikkan rating pada mesin pencari, dengan cara aktif di berbagai forum-forum berbagai komunitas untuk sekedar memeperkenalkan produk dan memberikan link ke web site perusahaan. (Odom, 2015)

c. Memanfaatkan Google Analytic yang terintegrasi dengan portal perusahaan untuk melihat efektifitas promo atau iklan yang dipasang pada berbagai saluran media sosial. (Omidvar, Mirabi, \& Shokry, 2011)

d. Mengunakan aplikasi komputer untuk meningkatkan kecepatan dan keakuratan bisnis. Terutama aplikasi untuk menangani keuangan perusahaan lalu aplikasi komputer untuk menangani persediaan dan stok produk jadi. (Turban \& Volonino, 2012). e. Menggunakan sistem berbasis SAAS untuk pengadaan aplikasi komputer sehingga efisien dan efektif karena tidak diperlukan investasi besar untuk membeli aplikasi, server dan tenaga TI, namun cukup mengadakan komputer untuk browsing internet dan menyediakan biaya sewa aplikasi yang lebih murah. (Turban \& Volonino, 2012)

f. Semua penjualan harus tercatat di Komputer, baik jenis produk yang terjual, jumlah item yang terjual, pembeli perorangan, distributor dan reseller, sehingga dapat dibuat berbagai analisa bisnis untuk melihat potensi mana yang dapat ditingkatkan untuk menaikkan omzet penjualan, Segmen pasar masingmasing tipe produk, sebaran geografis produk, masa puncak dan masa lesu penjualan, dsb. (Turban \& Volonino, 2012)

g. Meningkatan Customer Loyality dengan cara membangun database pelangan akhir, menyediakan sistem untuk menangani pesanan pelanggan, menerima keluhan dan masalah, dan melayani tanya jawab seputar produk baik lewat email atau lewat media chatting. (Buttle, 2009)

h. Meningkatkan Competitive Advantage perlu dilakukan dengan cara personalisasi 
produk dengan yang memungkinkan pelanggan untuk menentukan motif sprei, warna, dan hiasan secara on line. Lebih signifikan lagi jika pelanggan bisa menambahkan sekedar nama atau ucapan singkat pada sprei yang dipesan. (Porter, 2011)

\section{KESIMPULAN}

UKM Confetti mempunyai masalah yang sangat beragam. Kami mencoba mengurai permasalahan satu persatu dengan menawarkan beberapa solusi dengan memberikan worshop tentang bagaimana memanfaatkan Digital Marketing untuk memajukan pemasaran (Kingsnorth, 2019), membentuk badan Usaha berupa PT (Dewi, 2019), menggunakan aplikasi komputer baerbasis SAAS (Turban \& Volonino, 2012), menyusun Jobdesc yang jelas dari masingmasing peran karyawan agar lebih maksimal hasil kerjanya. Serta mengajarkan bagaimana mengelola manajemen kuangan dengan membuat laporan keuangan yang lebih profesional. Ilmu yang kami berikan sangat membantu mereka. Praktik langsung saat workshop juga kami lakukan. Hal ini sesuai dengan tujuan kami yaitu meningkatnya penjualan dengan pemasaran berbasis teknologi, mempunyai sumber daya manusia yang berkualitas, serta mampu melakukan pembukuan keuangan yang baik.

Dari pengamatan dan wawancara dengan pemilik dan pekerja baik di kantor dan di workshop, kemudian tim kami melakukan kajian dan analisa, maka kami melihat pertumbuhan bisnis dan prospek perusahaan ke depan kami mengusulkan agar dibentuk badan hukum berupa PT (Perseroan Terbatas) (Dewi, 2019). Untuk meningkatkan Branding Awareness kami mengusulkan agar perusahaan membuat desain Logo dan Brand dengan bentuk logo, warna dan font tulisan yang konsisten demikian juga pada semua situs web dan semua media sosial. Lebih bagus lagi logo dilengkapi dengan tagline yang selalu ditampilkan di bawah Logo dan Brand. (Rossiter, 2014). Mengenai manajemen khususnya struktur organisasi kami menyarankan dibuat struktur organisasi mendatar atau "Flat Organization" (Costa, 2018), karena dengan adanya komputerisasi maka seorang bisa merangkap beberapa bidang sekaligus, sehingga Implementasinya dibawah pemilik cukup satu General Manager yang bertanggung jawab menangani operasional, pemasaran dan keuangan. Pameran dan festival adalah salah satu tindakan pemasaran yang cukup terjangkau dan bisa mendapatkan lebih 
banyak manfaat seperti mengenal vendorvendor baru, mengetahui kompetitorkompetitor bisnis dan juga mendapatkan calon-calon pelanggan setia, untuk itu kami medorong UKM binaan kami untuk terus melakukan promosi dengan cara berpartisipasi mengikuti even-even seperti pameran dan festival. UKM juga perlu bergabung dengan beberapa komunitas yang memiliki jenis usaha yang sama, karena dengan begitu akan mendapatkan informasi seputar usaha yang dijalani. Saat ini hampir semua urusan bisnis bisa dipermudah dan dipercepat dengan Komputer, maka terakhir kami menyarankan agar UKM mulai menyisihkan labanya untuk berinvestasi di bidang IT. Penggunaaan teknologi Komputer yang tepat guna bisa menjadi salah satu point untuk dapat memenangkan persaingan bisnis yang semakin ketat.

\section{REFERENSI}

Buttle, F. (2009). Customer relationship management: Concepts and technology. In: Sydney: a Butterworth-Heinemann Title.

Chaffey, D., \& Ellis-Chadwick, F. (2019). Digital marketing: Pearson UK.

Costa, S. H. (2018). Consequence of Management Information System In Organizational Profit, Labor And Investment.

Dewi, L. P. (2019). Implementasi Peraturan Presiden Nomor 13 Tahun 2018 dalam Pendirian Perseroan Terbatas. Acta Comitas: Jurnal Hukum Kenotariatan, 4(1), 1-10.

Edmonds, T. P., Tsay, B.-Y., \& Olds, P. R. (2011). Fundamental managerial accounting concepts: McGraw-Hill.

Evans, D. (2010). Social media marketing: the next generation of business engagement: John Wiley \& Sons.

Indonesia, B. (2015). Profil bisnis usaha mikro, kecil dan menengah (UMKM). Kerjasama Lembaga Pengembangan Perbankan Indonesia (LPPI) dengan Bank Indonesia.

Indonesia, R., \& Dasar, U.-U. (1995). Undang Undang No. 9 Tahun 1995 Tentang: Usaha Kecil. Sekretariat Negara. Jakarta.

Indonesia, R., \& Keputusan Presiden, R. No. 99 Tahun 1998 tentang Bidang. Jenis Usaha yang dicadangkan untuk Usaha Kecil dan Bidang/Jenis Usaha yang Terbuka untuk Usaha Menengah atau Usaha Besar dengan Syarat Kemitraan.

Kingsnorth, S. (2019). Digital marketing strategy: an integrated approach to online marketing: Kogan Page Publishers.

Kotler, P., \& Armstrong, G. (2013). Principles of Marketing (16th Global Edition). In: Harlow: Pearson.

Kristiyanti, M. (2012). Peran strategis usaha kecil menengah (UKM) dalam pembangunan nasional. Majalah Ilmiah Informatika, 3(1), 63-89.

Kurnia, S. (2006). E-commerce adoption in developing countries: an Indonesian study. Paper presented at the San Diego international systems conference.

Maradina, J., Shanti, Y. K., Nadi, L., Kusumawardhany, S. S., \& Damayanti, R. J. A. (2019). Pemanfaatan Teknologi Untuk Mendukung Kesejahteraan Keluarga 
Dengan Berwirausaha. Abdimisi (1), 47-54.

Odom, S. (2015). SEO for 2016: The complete do-it-yourself SEO guide.

Omidvar, M. A., Mirabi, V. R., \& Shokry, N. (2011). Analyzing the impact of visitors on page views with Google analytics. arXiv preprint arXiv:1102.0735

Porter, M. E. (2011). Competitive advantage of nations: creating and sustaining superior performance: simon and schuster.

Rossiter, J. R. (2014). 'Branding'explained: Defining and measuring brand awareness and brand attitude. Journal of Brand Management, 21(7-8), 533 540.

Ryan, D. (2016). Understanding digital marketing: marketing strategies for engaging the digital generation: Kogan Page Publishers.

Suci, Y. R. (2017). Perkembangan UMKM (Usaha mikro kecil dan menengah) di Indonesia. Cano Ekonomos, 6(1), 5158.

Turban, E., \& Volonino, L. (2012). Information Technology For Management 5th Edition: Wiley.

Waldow, D., \& Falls, J. (2012). The Rebel's Guide to Email Marketing: Grow Your List, Break the Rules, and Win: Que Publishing.

Wankel, C., \& Stoner, J. A. (2009). Management education for global sustainability: IAP.

Wibawa, S. (2017). Tridharma Perguruan Tinggi (Pendidikan Dan Pengabdian Kepada Masyarakat). Disampaikan dalam Rapat Perencanaan Pengawasan Proses Bisnis Perguruan Tinggi Negeri. Yogyakarta, 29, 0115. 